\title{
Etiological and Clinical Evaluations of Patients with Acute Allograft Dysfunction Within the First Year
}

\author{
(1) Eren Soyaltın1, (1) Caner Alparslan¹, (1) Önder Yavaşcan¹, (1) Belde Kasap Demir²,

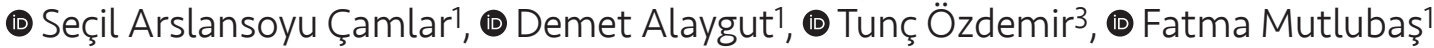 \\ 1University of Health Sciences Turkey, Tepecik Training and Research Hospital, Clinic of Pediatric Nephrology, İzmir, Turkey \\ 2ízmir Katip Çelebi University Faculty of Medicine, Department of Pediatric Nephrology and Rheumatology, İzmir, Turkey \\ 3University of Health Sciences Turkey, Tepecik Training and Research Hospital, Clinic of Pediatric Surgery, İzmir, Turkey
}

\begin{abstract}
Aim: Kidney transplantation is the most preferred long-term treatment of children with end stage renal disease since 1954. Graft dysfunction has been divided into three categories based on timing of presentation. In this article, we aim to present the etiologic factors of acute graft dysfunction in the first year of renal transplantation in children.

Materials and Methods: The patients, diagnosed with acute allograft dysfunction in first year of kidney transplantation, in University of Health Sciences Turkey, Tepecik Training and Research Hospital between March 2005 and October 2017 were analyzed prospectively in this study.

Results: Over the 15 year period, 56 pediatric renal allograft patients were followed in University of Health Sciences Turkey, Tepecik Training and Research Hospital. During this period, 25 patients had diagnosed with early allograft dysfunction. Five patients were admitted two times in a year with allograft dysfunction. The mean age of patients was $12.6(4.0 \pm 21.0)$ years, with a male and female ratio of 17:8. Delayed graft function was occurred in four patients (16\%). Among 25 renal allograft recipients showed early graft dysfunction on average of 4.2 months (1-10 months) after transplantation. The etiology of early graft dysfunction showed 10\% immunologic diseases and $90 \%$ non-immunologic factors. Five patients (16.7\%) diagnosed with urinary tract infection, one patient (3.3\%) diagnosed with cytomegalovirus nephropathy, five patients (16.7\%) diagnosed with BK nephropathy, eight patients (26.7\%) diagnosed with acute cyclosporine toxicity, seven patients (23.3\%) were diagnosed with dehydration and one patient (3.3\%) diagnosed with urologic anomalies. Twelve patients had performed renal allograft biopsy. The histological findings were consistent with T-cell mediated rejection in two patients; B-cell mediated rejection in one patient and viral nephropathy in five patients. Non-specific histological findings were determined in five patients.
\end{abstract}

Conclusion: Early recognition of the etiology of graft dysfunction that develops at 1 year and appropriate treatment will contribute to the preservation of long-term graft dysfunction.

Keywords: Renal transplantation, children, acute graft dysfunction

\section{Introduction}

Kidney transplantation has been the preferred longterm treatment of choice in children with end stage renal disease (ESRD) since 1954 (1). Prognosis and graft survival outcomes among pediatric transplant recipients has improved significantly over the past two decades as a result of improvements in surgical care, immunological management, infection control and improvements in 
cardiovascular care. However, allograft dysfunction (AGD) is the most common complication of renal transplantation and it has complex and critical outcomes for the long-term graft function and graft survival and can lead to graft loss $(1,2)$.

Acute renal AGD has been defined as one or more of the following criteria: an increase in serum creatinine over 25 percent from baseline, failure of serum creatinine to decrease following transplantation and/or proteinuria $>1$ gr/day (3). Graft dysfunction has been divided into three categories based on the timing of presentation: delayed graft function (DGF) in the first week after transplantation, early graft dysfunction within the first six months after transplantation and late graft dysfunction after six months. The approach to diagnosis and treatment of AGD is determined by this categorization. Post-operative graft dysfunction within the first week, known as DGF, mostly presents with failure in the decrease of serum creatinine and oliguria or anuria (4). In the initial post-transplant hours and days, surgical complications (urine leaks, urinary obstructions), thrombosis of the transplant renal artery or the transplant renal vein and hyperacute rejection tend to occur (4). In addition, expanded criteria donor kidneys have been associated with a higher risk of ischemic injury and DCF in this period (5). In the early period after transplantation, the most common causes of graft dysfunction have been reported to be acute rejection, calcineurin inhibitor nephrotoxicity, thrombotic microangiopathy, recurrence of primary disease, renal artery stenosis in the transplanted kidney, viral infections and de novo glomerular diseases $(4,5)$. There are a limited number of studies on early AGD in the literature and also these studies have focused on adults.

In this article, we aimed to present the etiological factors of treatment strategies for, and treatment responses to $A G D$ in the first year after renal transplantation in children.

\section{Materials and Methods}

The data of children with AGD in the first year after kidney transplantation between March 2005 and October 2017 were analyzed retrospectively in this study. All patients who had received a kidney transplant at less than 18 years of age were included. "ACD" was defined as an acute increase in creatinine levels by $25 \%$ or more compared to the baseline. AGD episodes within first year after transplantation are defined as early ADG. "DGF" was defined as the need for dialysis treatment during the first week after transplantation due to dysfunctional graft. Gender, age at the time of transplantation, the etiology of the chronic kidney disease, pre-transplant dialysis programs and durations, donor characteristics (living or cadaveric), heliotype matches, and the cold ischemia times of those patients diagnosed with $A G D$ were recorded. The patients were evaluated for $A G D$ episodes, time of diagnosis, increases in creatinine levels, and the presence and amount of proteinuria. The main causes of AGD were classified as either "immunological" or "non-immunological". Acute rejection, mediated by T-cells (acute cellular rejection) or antibodies (acute antibodymediated rejection) were classified as immunological causes; conversely, infections [urinary tract infections (UTIS)], dehydration, calcineurin inhibitors (CNIs) toxicity, viral nephropathy [Cytomegalovirus (CMV), BK virus infections] and urinary obstruction were grouped as nonimmunological factors. The number of biopsies for diagnosis and pathological findings were recorded. The treatments initiated according to the diagnoses and the responses to these treatments were evaluated according to decreases in creatinine and proteinuria levels. This retrospective analysis was approved by the local Ethics Committee, Izmir Katip Çelebi Non-Interventional Clinical Studies Institutional Review Board (date: 08/08/2019, no: 315).

\section{Statistical Analysis}

Categorical data were described using frequencies and percentages. Continuous data were described using the mean and standard deviation for normally distributed data. The distribution of baseline characteristics across categories of the exposure variable was evaluated using parametric statistics as appropriate. All statistical analyses were performed using SPSS version 18.0.

\section{Results}

Over the 12-year period, 55 pediatric renal allograft patients were followed up in our clinic. During this long follow-up period, 25 patients (45\%) were diagnosed with early AGD with 30 AGD episodes in total (five patients were admitted twice in the first year). The mean age of the patients was $12.6(4.0 \pm 21.0)$ years, with a male to female ratio of approximately 2:1. Sixty percent of patients received renal allograft from a living donor and $40 \%$ of patients received renal allograft from a deceased donor. All living donors were related donors such as the parents of the patients. The underlying etiologies of ESRD were congenital urologic abnormalities in 14 (56\%), chronic pyelonephritis in five $(20 \%)$, chronic tubulopathy in two $(8 \%)$, hemolytic uremic syndrome in one $(4 \%)$, amyloidosis in one (4\%) and renal cystic disease in two (8\%) cases. Five children (39\%) had pre-emptive transplantation, 12 children (61\%) had a transplant after a variable duration 
of peritoneal dialysis and 8 children had a transplant after a period of hemodialysis. The average duration of the dialysis program was 31.2 months (1-120 months). Five recipients showed one heliotype match, four recipients showed two heliotype matches, seven recipients showed three heliotype matches, eight recipients showed four heliotype matches and only one recipient showed five heliotype matches. The mean cold ischemia time for renal allograft was 7.4 hours (1-24 hours). Zero-time allograft biopsies were mostly reported (21 patients) as normal glomerular morphology. Allograft biopsy materials revealed minimal intimal sclerosis in one patient and acute tubular necrosis in two recipients. The allograft biopsy report of a recipient who had transplantation in another center was missing. DGF occurred in four patients (16\%). The allograft functions improved over an average of five days in these recipients (Table I).

Patients had early AGD at an average of 4.2 months (1-10 months) after transplantation. The mean level of increase in creatinine was $0.66 \mathrm{mg} / \mathrm{dL}(0.3-3.5 \mathrm{mg} / \mathrm{dL})$. Urine analysis revealed non-nephrotic proteinuria in 14 patients and nephrotic proteinuria in three patients at the time of diagnosis. Proteinuria was not observed in 13 patients. The underlying etiologies of early AGD were immunologic in $10 \%$ and non-immunologic in $90 \%$. Non-immunologic factors were UTI in five (16.7\%), CMV nephropathy in one (3.3\%), BK nephropathy in five (16.7\%), acute CNI toxicity in eight (26.7\%), dehydration in seven (23.3\%) and urological anomalies in one patient (3.3\%) respectively. Upon the diagnosis of AGD, 12 patients underwent renal allograft biopsy. Histological findings were consistent with T-cell mediated rejection in two patients (8\%); B-cell mediated rejection in one patient (4\%) and viral nephropathy in five patients (20\%). Non-specific histological findings were determined in five patients. In 18 AGD episodes, biopsy was not performed.

For AGD treatment, intravenous hydration was performed in seven patients. Antibiotic treatment was given to six patients with graft dysfunction due to UTI, and antiviral protocols were applied to five patients who were diagnosed with viral nephropathy. CNI dose was regulated in eight patients who had acute CNI toxicity. One patient who had post-renal obstruction in the transplant kidney was surgically treated. Two patients who were diagnosed with acute cellular rejection as the cause of AGD received pulse corticosteroid and one patient with B-cell mediated rejection received pulse corticosteroid and intravenous immunoglobulin. In the follow-up of the patients, mean creatinine level decreased $0.5 \mathrm{mg} / \mathrm{dL}(-3.0-0.0)$ by the end

\begin{tabular}{|c|c|}
\hline No of AGD patient/All patient, $n(\%)$ & $25 / 56(44.6)$ \\
\hline Gender (female/male), n (\%) & $8(32) / 17(68)$ \\
\hline Tx age, (year) (min-max, mean \pm SD) & $4-21,12.6 \pm 4.3$ \\
\hline Tx donor (living/chadaveric), n (\%) & $15(60) / 10(40)$ \\
\hline \multicolumn{2}{|l|}{ Etiology of CKD, $n$ (\%) } \\
\hline Urological (CAKUT) & $14(56)$ \\
\hline Non-urological & $11(44)$ \\
\hline Chronic glomerulonephritis & $5(20)$ \\
\hline Chronic tubulopathy & $2(8)$ \\
\hline Renal cystic disease & $2(8)$ \\
\hline HUS & $1(4)$ \\
\hline Amiloidosis & $1(4)$ \\
\hline \multicolumn{2}{|l|}{ Dialysis types, n (\%) } \\
\hline Preemptive & $5(20)$ \\
\hline PD & $12(48)$ \\
\hline HD & $8(32)$ \\
\hline $\begin{array}{l}\text { Duration of dialysis (year) (min-max, } \\
\text { mean } \pm \text { SD) }\end{array}$ & $0.1-10,2.6 \pm 2.2$ \\
\hline $\begin{array}{l}\text { Residue urine volume (anuria/oliguria/ } \\
>500 \mathrm{cc}), \mathrm{n}(\%)\end{array}$ & $4(16) / 5(20) / 16(64)$ \\
\hline \multicolumn{2}{|l|}{ HLA match } \\
\hline 1 match & 5 \\
\hline 2 match & 4 \\
\hline 3 match & 7 \\
\hline 4 match & 8 \\
\hline 5 match & 1 \\
\hline DGD, n (\%) & $4 / 25(16)$ \\
\hline $\begin{array}{l}\text { Cold ischemia time (hour) (min-max, } \\
\text { mean } \pm \text { SD) }\end{array}$ & $1-24,7.4 \pm 7.9$ \\
\hline $\begin{array}{l}\text { Urine volume in first hour after } \mathrm{Tx}(\mathrm{cc}) \\
\text { (min-max, mean } \pm \text { SD) }\end{array}$ & $250-10,100,4081 \pm 2830$ \\
\hline \multicolumn{2}{|l|}{ Zero-time renal transplant biopsy n (\%) } \\
\hline Normal & $21(84)$ \\
\hline Generalized ATN & $2(8)$ \\
\hline Mild intimal sclerosis & $1(4)$ \\
\hline Missed & $1(4)$ \\
\hline \multicolumn{2}{|c|}{$\begin{array}{l}\text { AGD: Acute graft dysfunction, DGD: Delayed graft function, TX: Transplantation, } \\
\text { SD: Standard deviation, CKD: Chronic kidney disease, CAKUT: Congenital } \\
\text { abnormalities of kidney urinary tract, HUS: Hemolytic uremic syndrome, } \\
\text { PD: Peritoneal dialysis, HD: Hemodialysis, ATN: Acute tubular necrosis, min: } \\
\text { Minimum, max: Maximum }\end{array}$} \\
\hline
\end{tabular}

of the first week, $0.49 \mathrm{mg} / \mathrm{dL}(-3.0-0.0)$ by the end of the second week, $0.48 \mathrm{mg} / \mathrm{dL}(-2.9-0.4)$ by the end of the third week and $0.56 \mathrm{mg} / \mathrm{dL}(-3.40-0.20)$ by the end of the fourth 
week. Four weeks after the treatment, mean creatinine levels decreased $0.56 \mathrm{mg} / \mathrm{dL}$. Nephrotic proteinuria was detected in two, and non-nephrotic proteinuria was detected in 12 cases (Table II). Creatinine levels did not decrease to basal level in eight patients. Three of these patients were diagnosed with BK virus nephropathy, three had UTIs, and one patient had B-cell mediated rejection. All patients with AGD secondary to acute dehydration, CNI toxicity, urological and vascular pathologies were detected to have decreased to basal values of creatine levels after treatment.

\section{Discussion}

AGD is the most common complication of renal transplantation thatcanlead tograft loss. It usuallymanifests as an increase in the serum creatinine concentration with a decrease in the estimated glomerular filtration rate (eGFR) (4). Proteinuria, renal tubular dysfunction and reduction in urine output are the other presentations of AGD (4). There are several causes of early AGD. Some causes tend to occur in the initial post-transplant hours and days whereas others occur in the first few weeks and months after transplantation (4). Hyperacute rejection and thrombosis of the renal artery or vein are serious causes of early ACD that occur in the initial hours after transplantation (6). Neither thrombosis nor hyperacute rejection were detected as a cause of early ACD in any of our patients.

The most frequent cause of AGD is toxicity from CNI that are used in transplantation for their high effectivity in preventing allograft rejection. ACD caused by $\mathrm{CNI}$ can occur acutely in a reversible form leading to irreversible structural damage, and it can be attributed to contribution of chronic calcineurin toxicity to long-term renal $\operatorname{AGD}(7,8)$. Nephrotoxicity secondary to CNIs has been reported to occur in $76 \%$ to $94 \%$ of kidney transplant recipients (9). In previous studies, $\mathrm{CNI}$ toxicity has been shown in two retrospective case-control studies and 10 cohort studies. $\mathrm{CNI}$ toxicity was defined by renal biopsy in five studies, with clinical indexes (eGFR/Scr/FK506 concentration) in four studies and with DGF-designated in three studies. In five studies, patients received cyclosporine treatment while in seven studies they received tacrolimus therapy (10-22). In our study, it was found that 8 of the 30 acute cases of AGD were due to calcineurin toxicity.

Immunosuppressive drugs improve renal graft survival and function, but it has been proven that they contribute significantly to most post-transplantation infectious diseases (23). Gastrointestinal infections are the most common infectious diseases adversely affected

\begin{tabular}{|c|c|}
\hline $\begin{array}{l}\text { No of } A G D / \text { No of patient with AGD/ } \\
\text { All patient, }(n)\end{array}$ & $30 / 25 / 56$ \\
\hline $\begin{array}{l}\text { AGD time after transplantation } \\
\text { (month), (min-max, mean } \pm \text { SD) }\end{array}$ & $1-10,4.2 \pm 2.3$ \\
\hline \multicolumn{2}{|l|}{ Etiology of AGD, n (\%) } \\
\hline Immunologic & $3(10)$ \\
\hline T-cell rejection & $2(6.6)$ \\
\hline B-cell rejection & $1(3.4)$ \\
\hline Non-immunologic & $27(90)$ \\
\hline Infection & $18(60)$ \\
\hline AGE-induced dehydratation & $7(23.3)$ \\
\hline UTI & $5(16.7)$ \\
\hline BKV & $5(16.7)$ \\
\hline CMV & $1(3.3)$ \\
\hline CNI toxicity & $8(26.7)$ \\
\hline Ureterovesical obstruction & $1(3.3)$ \\
\hline AGD biopsy findings, $\mathrm{n}(\%)$ & $12 / 30(40)$ \\
\hline Non-specific & $5(41.7)$ \\
\hline Viral nephropathy & $4(33.3)$ \\
\hline T-cell rejection & $2(16.7)$ \\
\hline B-cell rejection & $1(8.3)$ \\
\hline \multicolumn{2}{|l|}{ Treatment, n (\%) } \\
\hline $\mathrm{CNI}$ dose regulation & $8(26.6)$ \\
\hline IV hydration & $7(23.4)$ \\
\hline Antibiotic & $6(20)$ \\
\hline Antiviral & $5(16.6)$ \\
\hline Steroid+IVIG & $3(10)$ \\
\hline Graft ureteroneocystostomy & $1(3.4)$ \\
\hline \multicolumn{2}{|c|}{$\Delta$ creatinine, $(\mathrm{mg} / \mathrm{dL})(\min -\mathrm{max}$, mean $\pm \mathrm{SD})$} \\
\hline During AGD & $(0.3-2),(0.56 \pm 0.38)$ \\
\hline After 4 weeks AGD & $\begin{array}{l}{[(-1.9)-(-0.2)],[(-0.47)} \\
\pm(-0.49)]\end{array}$ \\
\hline \multicolumn{2}{|c|}{$\begin{array}{l}\text { No of patient with proteinuria, (nephrotic/non-nephrotic/ } \\
\text { normal) (n) }\end{array}$} \\
\hline During AGD & $3 / 12 / 10$ \\
\hline After 4 weeks AGD & $3 / 12 / 10$ \\
\hline \multicolumn{2}{|c|}{$\begin{array}{l}\text { AGD: Acute graft dysfunction, Tx: Transplantation, SD: Standard deviatio } \\
\text { AGE: Acute gastroenteritis, UTI: Urinary tract infection, BKV: BK virus CM } \\
\text { Cytomegalovirus, CNI: Calcineurin inhibitors, min: Minimum, max: Maximun }\end{array}$} \\
\hline
\end{tabular}

by immunosuppression in transplant recipients. The major symptoms are abdominal pain, diarrhea, nausea, vomiting and dyspepsia, which are inconvenient and unpleasant for the patient (24). With infected enterocytes, changes 
in immunosuppressive drug metabolism occur and irregular blood drug levels can be seen. These infections are associated with an increased risk of AGD due to dehydration and irregular immunosuppressive drug levels $(25,26)$. In a DIDACT study that defined the etiology and treatment of severe diarrhea in renal graft recipients, $67 \%$ of patients were diagnosed with AGD (24). We observed seven renal transplant recipients (23\%) with AGD secondary to gastrointestinal infections and hypovolemia in 30 early AGD periods.

The second most frequent infectious complication is UTIs (27). Some studies have evaluated the impact of UTIs on renal allograft function (27-30). Studies evaluating all UTIs concluded that UTIs do not cause $\operatorname{AGD}(28,29)$; however, there is still no definitive conclusion. Pelle et al. (30) associated UTIs with impaired renal allograft function measured by eGFR within 4 years of follow-up time in kidney allograft recipients. Singh et al. (27) observed impaired renal allograft function measured by eGFR and 24-hour urine protein excretion during UTIs. The allograft functions were normalized in all patients within one month subsequent to treatment of UTIs. Similar to these studies, in our study, UTI was the etiology of early AGD in 5 patients and graft functions normalized with treatment in all of them.

BK virus is an opportunistic infectious virus, threatening renal function especially during the first year after transplantation (31). The virus remains latent in genitourinary cells after primary infection and can reactivate in immunocompromised kidney transplant recipients usually in the first year. Tubulointerstitial nephritis is frequently seen in the early period of infection while ureteral stenosis may occur in the late period (32). In one research study, the mean rate of graft loss due to BK virus nephropathy was reported to be $46.2 \%$ and in another study the rate of allograft loss was reported to be higher than the above-mentioned average $(66.7 \%)(33,34)$. In our study, BK virus nephropathy was determined in five patients (16.7\%). All cases with BK nephropathy were treated by immunosuppressive dose reduction and intravenous immunoglobulin. Mycophenolate mofetil treatment was discontinued and leflunomide treatment was started in 3 patients who could not achieve the expected decrease in BK virus copy levels and continued graft dysfunction. Creatinine levels were reduced to basal levels in only two patients after four weeks of treatment and in other patients, creatinine levels decreased to basal levels after leflunomide treatment during the fourth month. In one patient, the etiology of early acute graft dysfunction was CMV, another opportunistic viral infection. After CMV treatment was applied to this patient, their creatinine value decreased to a basal value.

Acute rejection is one of the causes of early graft dysfunction and can occur due to T-cell mediated cellular rejection or antibody-mediated acute humoral rejection (32). The incidence of acute allograft rejection for first-year posttransplant patients was reported to be $8 \%$ by the Organ Procurement and Transplantation Network in 2014 (2). Most acute rejection episodes were reported among the first six months after transplantation and most patients with acute rejection episodes are asymptomatic. Patients usually present with an increase in creatinine level, and rarely with a reduction in urine output, graft pain or tenderness (35). In our study, acute rejection was determined to be $10 \%$ in acute graft failures in the first year in accordance with the literature. In the biopsies of cases with acute rejection, T-cell rejection was determined in two cases and B-cell rejection was determined in one case. All cases presented with acute graft failure and there was no clinical symptom in any case.

Another complication of renal transplantation which causes $A G D$ is ureteral or bladder related obstructive uropathy $(32,36)$. Ureteral obstruction can be caused by extrinsic pathologies (compression by urinoma, lymphocele, or hematoma) or intrinsic factors (ureteral edema, blood clots, stones, or strictures). Ureteral stenosis is reported to occur in $2.4 \%$ to $6.5 \%$ of kidney transplants (37). Most ureteral complications were reported to occur during the first year after renal transplantation (32). In our study, urological pathology causing renal graft failure in first year of transplantation was determined in only one patient. In addition, the cause of the ureteral obstruction was not related to the transplantation surgery. A hematoma formed after surgical procedure for post-transplant vesicoureteral reflux in the post-transplant $6^{\text {th }}$ month causing ureteral stenosis and graft failure.

There are few studies and reports on acute graft dysfunctions and its etiology in the first year after renal transplantation. In the present study of the etiology of early $A G D$, it can be seen that the ratio of immunological etiologies is lower compared with previous studies $(37,38)$. However, high blood levels of CNI that frequently associated with immunosuppressive drugs and UTIs are seen at a higher rate in ACD etiology in our study. The causes of early graft dysfunction may vary with medical and surgical treatment modalities which can change over time. The determination of the causes of graft dysfunction and its early treatment can lead to improvements in graft survival and prognosis. 


\section{Conclusion}

In conclusion, non-immunologic causes of early AGD have been observed with the increase in the effectiveness of immunosuppressive therapies. Early recognition and appropriate treatment of AGD etiology can contribute to a rapid recovery of graft function.

\section{Ethics}

Ethics Committee Approval: This retrospective analysis was approved by the local Ethics Committee, Izmir Katip Çelebi Non-Interventional Clinical Studies Institutional Review Board (date: 08/08/2019, no: 315).

Informed Consent: Retrospective study.

Peer-review: Externally peer-reviewed.

\section{Authorship Contributions}

Concept: Ö.Y., Design: B.K.D., Data Collection or Processing: E.S., Analysis or Interpretation: S.A.Ç., Literature Search: F.M., Writing: E.S., Ö.Y., D.A., C.A., T.Ö.

Conflict of Interest: No conflict of interest was declared by the authors.

Financial Disclosure: The authors declared that this study received no financial support.

\section{References}

1. Roach IP, Bock ME, Goebel J. Pediatric kidney transplantation. Semin Pediatr Surg 2017; 26:233-40.

2. Hart A, Smith JM, Skeans MA, et al. OPTN/SRTR 2015 Annual Data Report: Kidney. Am I Transplant 2017; 17(Suppl 1):21-116.

3. Kadambi PV, Brennan DC, Chon WJ. Evaluation and diagnosis of the patient with renal allograft dysfunction. UpToDate 2017.

4. Goldberg RJ, Weng FL, Kandula P. Acute and chronic allograft dysfunction in kidney transplant recipients. Med Clin North Am 2016; 100:487-503.

5. Wan SS, Cantarovich M, Mucsi I, Baran D, Paraskevas S, Tchervenkov J. Early renal function recovery and long-term graft survival in kidney transplantation. Transpl Int 2016; 29:619-26.

6. Matas AJ, Humar A, Gillingham KJ, et al. Five preventable causes of kidney graft loss in the 1990s: a single-center analysis. Kidney Int 2002; 62:704-14.

7. Fernando M, Peake PW, Endre ZH. Biomarkers of calcineurin inhibitor nephrotoxicity in transplantation. Biomark Med 2014; 8:1247-62.

8. Zununi Vahed S, Ardalan M, Samadi N, OmidiY. Pharmacogenetics and drug-induced nephrotoxicity in renal transplant recipients. Bioimpacts 2015; 5:45-54.

9. Joy MS, Hogan SL, Thompson BD, Finn WF, Nickeleit V. Cytochrome P450 3A5 expression in the kidneys of patients with calcineurin inhibitor nephrotoxicity. Nephrol Dial Transplant 2007; 22:1963-8.
10. Xia $T$, Zhu $S$, Wen $Y$, et al. Risk factors for calcineurin inhibitor nephrotoxicity after renal transplantation: a systematic review and meta-analysis. Drug Des Devel Ther 2018; 12:417-28.

11. Boom H, Mallat MJ, de Fijter JW, Paul LC, Bruijn JA, van Es LA. Calcium levels as a risk factor for delayed graft function. Transplantation 2004; 77:868-73.

12. Bröcker V, Schubert V, Scheffner I, et al. Arteriolar lesions in renal transplant biopsies: prevalence, progression, and clinical significance. Am / Pathol 2012; 180:1852-62.

13. Cattaneo D, Ruggenenti P, Baldelli S, et al. ABCB1 genotypes predict cyclosporine-related adverse events and kidney allograft outcome. I Am Soc Nephrol 2009; 20:1404-15.

14. Naesens M, Lerut E, Damme BV, Vanrenterghem Y, Kuypers DRJ. Tacrolimus exposure and evolution of renal allograft histology in the first year after transplantation. Am / Transplant 2007; 7:2114-23.

15. Satoh S, Saito $M$, Inoue T, et al. CYP3A5 ${ }^{*} 1$ allele associated with tacrolimus trough concentrations but not subclinical acute rejection or chronic allograft nephropathy in Japanese renal transplant recipients. Eur J Clin Pharmacol 2009; 65:473-81.

16. Stratta P, Quaglia M, Cena T, et al. The interactions of age, sex, body mass index, genetics, and steroid weight-based doses on tacrolimus dosing requirement after adult kidney transplantation. Eur J Clin Pharmacol 2012; 68:671-80.

17. Yagisawa $T$, Omoto $K$, Shimizu $T$, Ishida $H$, Tanabe $K$. Arteriosclerosis in zero-time biopsy is a risk factor for tacrolimusinduced chronic nephrotoxicity. Nephrology (Carlton) 2015; 20(Suppl 2):51-7.

18. Yan L, Li Y, Tang IT, An YF, Wang LL, Shi YY. Donor ABCB1 3435 C.T genetic polymorphisms influence early renal function in kidney transplant recipients treated with tacrolimus. Pharmacogenomics 2016; 17:249-57.

19. Cho JH, Huh S, Kwon TG, Choi JY. Association of C-509T and T869C polymorphisms of transforming growth factor-beta1 gene with chronic allograft nephropathy and graft survival in Korean renal transplant recipients. Transplant Proc 2008; 40:2355-60

20. Hazzan M, Hertig A, Buob D, et al. Epithelial-to-mesenchymal transition predicts cyclosporine nephrotoxicity in renal transplant recipients. I Am Soc Nephrol 2011; 22:1375-81.

21. Hauser IA, Schaeffeler E, Gauer S, et al. ABCB1 genotype of the donor but not of the recipient is a major risk factor for cyclosporine-related nephrotoxicity after renal transplantation. . Am Soc Nephrol 2005; 16:1501-11.

22. García M, Macías RM, Cubero J), Benítez J, Caravaca F, Gervasini G. ABCB1 polymorphisms are associated with cyclosporine-induced nephrotoxicity and gingival hyperplasia in renal transplant recipients. Eur J Clin Pharmacol 2013; 69:385-93.

23. Anastasopoulos NA, Duni A, Peschos D, Agnantis N, Dounousi E. The spectrum of infectious diseases in kidney transplantation: a review of the classification, pathogens and clinical manifestations. In Vivo 2015; 29:415-22.

24. Maes B, Hadaya K, de Moor B, et al. Severe diarrhea in renal transplant patients: results of the DIDACT study. Am / Transplant 2006; 6:1466-72. Erratum in: Am J Transplant 2007; 7:729. 
25. Bhadauria D, Goel A, Kaul A, et al. Cryptosporidium infection after renal transplantation in an endemic area. Transpl Infect Dis 2015; 17:48-55.

26. Bonatti H, Barroso LF II, Sawyer RG, Kotton CN, Sifri CD. Cryptosporidium enteritis in solid organ transplant recipients: multicenter retrospective evaluation of 10 cases reveals an association with elevated tacrolimus concentrations. Transpl Infect Dis 2012; 114:635-48.

27. Singh $\mathrm{R}$, Geerlings $\mathrm{SE}$, Peters-Sengers $\mathrm{H}$, et al. Incidence, risk factors, and the impact of allograft pyelonephritis on renal allograft function. Transpl Infect Dis 2016; 18:647-60.

28. Wojciechowski D, Chandran S. Effect of ciprofloxacin combined with sulfamethoxazoletrimethoprim prophylaxis on the incidence of urinary tract infections after kidney transplantation. Transplantation 2013; 96:400-5.

29. Golebiewska JE, Debska-Slizien A, Rutkowski B. Urinary tract infections during the first year after renal transplantation: one center's experience and a review of the literature. Clin Transplant 2014; 28:1263-70.

30. Pelle G, Vimont S, Levy PP, et al. Acute pyelonephritis represents a risk factor impairing long-term kidney graft function. Am J Transplant 2007; 7:899-907.

31. Krejci K, Tichy T, Bednarikova J, Zamboch K, Zadrazil J. BK virusinduced renal allograft nephropathy. Biomed Pap Med Fac Univ Palacky Olomouc Czech Repub 2018; 162:165-77.
32. Goldberg RJ, Weng FL, Kandula P. Acute and chronic allograft dysfunction in kidney transplant recipients. Med Clin North Am 2016; 100:487-503.

33. Hirsch HH, Brennan DC, Drachenberg CB, et al. Polyomavirusassociatednephropathyin renaltransplantation:interdisciplinary analyses and recommendations. Transplantation 2005; 79:127786.

34. Park WY, Kang SS, Jin K, Park SB, Choe M, Han S. Longterm prognosis of BK virus-associated nephropathy in kidney transplant recipients. Kidney Res Clin Pract 2018; 37:167-73.

35. Pham, PTT, Nast, et al. Diagnosis and Therapy of Graft Dysfunction. In: Periera BJG, Sayegh MH, Blake P (eds). Chronic Kidney Disease, Dialysis and Transplantation. $2^{\text {nd }}$ ed. Philadelphia, Elsevier Saunders, 2005:641.

36. Dreikorn K. Problems of the distal ureter in renal transplantation. Urol Int 1992; 49:76-89.

37. Hadiuzzaman KM, Islam SF, Faroque MO, et al. Etiology of early renal allograft dysfunction and comparison between dysfunction and function group: a single center study. Mymensingh Med ) 2017; 26:748-55.

38. Zhang I, Qiu I, Chen GD, et al. Etiological analysis of graft dysfunction following living kidney transplantation: a report of 366 biopsies. Ren Fail 2018; 40:219-25. 